INFLUENCIA DO TAMANHO DAS SEMENTES NO DESENVOLVIMENTO E PRODUÇÃO DE PLANTAS DE SO-

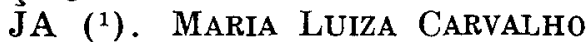
Carelli $\left({ }^{2}\right)$ e JoEl IRINEU FaHL. A qualidade da semente é um parâmetro preponderante no desenvolvimento das plantas. O sucesso no estabelecimento de uma cultura está diretamente relacionado, entre outros fatores, ao potencial de viabilidade, ao potencial genético e ao material de reserva das sementes.

Nas leguminosas, ao contrário das gramíneas, a influência do tamanho das sementes sobre o comportamento de plantas não está bem definida, e os dados de literatura são contraditórios. Handenburg, citado por RIES $\left({ }^{3}\right)$, não encontrou diferença na produção de plantas de feijão obtidas de lotes de sementes de diferentes tamanhos. Entretanto, WESTER ( $\left.{ }^{4}\right)$ relata que as maiores sementes de feijão originaram plantas de melhor desenvolvimento e maior produtividade. FIGUEIREDO \& VIEIRA $\left({ }^{5}\right)$, estudando as variedades de feijão-rico-23 e mantei- gão-fosco 11, constataram que, na primeira variedade, o tamanho da semente afetou o "stand", a altura das plantas e a produção, ao passo que, na segunda, nenhuma dessas características foi afetada.

EDWARDS \& HARTWIG $\left({ }^{6}\right)$, em estudos efetuados com linhagens isogênicas de soja que diferiam no tamanho das sementes, verificaram que as plântulas originadas de sementes pequenas e médias apresentavam emergência mais rápida e maior desenvolvimento radicular do que as provenientes de sementes grandes. JOHNSON \& LUEDDERS ( $\left.{ }^{7}\right)$ não encontraram diferenças significativas na emergência e produção de plantas de soja obtidas de sementes de vários tamanhos. Entretanto, BURRIS; EDJE \& WAHAB ( $\left.{ }^{8}\right)$, estudando o comportamento de tamanhos diversos de sementes em quatro variedades de soja, verificaram que as três classes maiores de sementes apresentavam taxas superiores de emergência, área foliar e produção. GODOY et alii $\left({ }^{9}\right)$ também concluíram que a germinação foi diretamente proporcional ao ta-

1) Trabalho apresentado na 30. a Reunião Anual da SBPC, realizada em São Paulo (SP), em julho de 1978. Recebido para publicação em $25 / 09 / 1978$

(2) Com bolsa de suplementação do CNPq.

(i) RIES, S. K. The relationship of protein content and size of bean seed with growth and yield. J. Am. Soc. hort. Sci., 96(5):557-560, 1971.

(1) WESTER, R. E. Effects of size seed on plant growth and yield of Fordhook 242 bush lima bean. Froc. Am. Soc. hort. Sci., 84:327-331, 1964.

(5) FIGUEIREDO, M. S. \& VIEIRA, C. Efeito do tamanho das sementes sobre o "stand", produçāo e altura das plantas, na cultura do feijão (Phaseolus vulgaris L.). R. Ceres, Viçosa, 17(91):47-60, 1970.

(i) EDWARDS, C. J. \& HARTWIG, E. E. Effects of seed size upon rate of germination in soybeans. Agron. J., Washington, 63:429-430, 1971 .

(i) JOHNSON, D. R. \& LUEDDERS, U. D. Effect of planted seed size on emergence and yield of soybeans (Glycine $\max$ L. Merr.). Agron. J., Washington, 66:117-118, 1974.

(8) BURRIS, J. S.; EDJE, O. T. \& WAHAB, A. H. Effects of seed size on seedling performance in soybeans. II. Seedling growth and photosynthesis and field performance. Crop. Sci, Madison, $13: 207-210,1973$.

(') GODOY, R.; ABRAHÃO, J. T. M.; MARCUS FILHO, J. \& BRAGANTINI, C. Influência do tamanho sobre a conservação, germinação e vigor de sementes de soja (Glycine max L. Merr.). Anais da E. S. A. "Luiz de Queiroz", Piracicaba, 31:187-206, 1974. 
manho das sementes, nos três cultivares de soja estudados (santa-rosa, viçoja e IAC-2).

O objetivo deste trabalho foi verificar se o tamanho das sementes influenciaria o posterior desenvolvimento de plantas de soja santa-rosa, que é um dos cultivares mais plantados no Estado de São Paulo.

Material e método: Sementes de soja, cultivar santa-rosa, foram divididas em dois lotes de acordo com o tamanho: aquelas retidas na peneira $17 / 64$ de polegada foram denominadas "grandes", e as retidas na peneira $15 / 64$ de polegada, "pequenas".

Para avaliar a influência do tamanho da semente no desenvolvimento e produção das plantas, foram instalados experimentos em casa de vegetação e em condiçōes de campo. Em ambos os casos, antes do plantio, as sementes foram inoculadas com Rhizobium japonicum, em inoculante turfoso preparado com mistura em partes iguais das estirpes SMS $65\left({ }^{10}\right) \mathrm{e}$ SMS $313\left(^{*}\right)$ altamente eficiente para o cultivar santa-rosa.

O plantio foi efetuado a 16 de novembro de 1976 , simultaneamente em casa de vegetação e no campo. Em casa de vegetação, colocaram-se, para germinar, quatro sementes por vaso, no qual permaneceram duas plantas, após o desbaste efetuado ao acaso. Fo- ram feitas duas amostragens, uma para avaliar $o$ desenvolvimento das plantas e, outra, os componentes da produção. $\mathrm{Na}$ primeira, 70 dias após o plantio, os parâmetros analisados foram área foliar e peso da matéria seca da parte aérea e das raízes. Na segunda, aos 180 dias, ou seja, no final do ciclo da planta, foram determinados os seguintes parâmetros: peso da matéria seca das vagens vazias, número de vagens e de grãos e peso dos grãos por vaso (duas plantas). Todas as amostragens foram feitas com sete repetições para cada tamanho de semente. Os pesos da matéria seca foram determinados através de secagem do material vegetal em estufa (a $60^{\circ} \mathrm{C}$ durante cinco dias), e a área foliar foi medida em integrador de área, modelo portátil.

O experimento de campo foi instalado no Centro Experimental de Campinas, em latossolo roxo, cuja análise química revelou os seguintes resultados: $\mathrm{pH} 5,9$, matéria orgânica $3,3 \%, \mathrm{Al}^{3+} 0,0$; $\mathrm{Ca}^{2+} 2,0 ; \mathrm{Mg}^{2+} 0,5$ meq por $100 \mathrm{ml}$ de T.F.S.A.; $\mathrm{K}^{+} 151,0$ e P $1,0 \mu \mathrm{g} / \mathrm{ml}$ de T.F.S.A. Foram aplicados $60 \mathrm{~kg} / \mathrm{ha}$ de $\mathrm{P}_{2} 0_{5}, 90 \mathrm{~kg} /$ /ha de $\mathrm{CaO}$ e $54 \mathrm{~kg} / \mathrm{ha}$ de $\mathrm{MgO}$, na forma de termofosfato, distribuído a lanço e incorporado ao solo 20 dias antes do plantio. Em condições de campo, foram plantadas quatro linhas de 3 metros de comprimento, espaçadas de $0,70 \mathrm{~m}$, com cinco repetições.

\footnotetext{
(io) LOPES, E. S.; GIARDINI, A. R.; KIIHL, R. A. S. \& IGUE, T. Especificidade hospedeira e pre-seleção de estirpes de Rhizobium japonicum para as variedades santa-rosa, viçoja e IAC 2 de soia. Bragantia, Campinas, 35:1-11, 1976.

(*) LOPES, E. S. Informação pessoal, 1976.
} 
As duas linhas centrais continham os tratamentos (uma para cada tamanho de semente) e as linhas externas foram consideradas como bordaduras. Em campo, avaliou-se somente a produção, que foi determinada pelo peso dos grãos das plantas contidas nos dois metros centrais das linhas internas.

Resultados e discussão: Os pesos de 1.000 sementes, determinados de acordo com as Regras para Análise de Sementes do $\mathrm{Mi}$ nistério da Agricultura, BRASIL (11) foram 105,2 e 202,4g, respectivamente para as sementes pequenas e grandes.
Os resultados das determinações do peso da matéria seca da parte aérea e das raízes e a área foliar das plantas após 70 dias do plantio, quando ocorre o máximo acúmulo de matéria seca $\left({ }^{12}\right)$, estão expressos no quadro 1. Como se pode observar, o tamanho das sementes não influenciou o crescimento das plantas cultivadas em casa de vegetação.

Os dados referentes ao efeito do tamanho das sementes nos componentes da produção das plantas cultivadas em casa de vegetação são apresentados no quadro 2. Aparentemente, houve al.

QUADRO 1. Pesos da matéria seca da parte aérea e das raízes e área foliar por duas plantas de soja cultivadas em casa de vegetação, 70 dias após o plantio. Média de sete repetiçōes

\begin{tabular}{lccc}
$\begin{array}{c}\text { Tamanho } \\
\text { de sementes }\end{array}$ & Parte aérea & Raízes & Area foliar \\
\hline & $\mathrm{g}$ & $\mathrm{g}$ & $\mathrm{dm}^{2}$ \\
Pequenas & 13,51 & 6,40 & 25,33 \\
Grandes & 13,12 & 5,85 & 26,81 \\
\hline
\end{tabular}

QUADFO 2. Peso da matéria seca das vagens vazias, número de vagens e de grãos e peso dos grāos por duas plantas de soja cultivadas em casa de vegetąāo, no final do ciclo. Média de sete repetiçōes

Tamanho de sementes
M. S. vagens vazias
N. ${ }^{\circ}$ de vagens N. ${ }^{\circ}$ de gräos
Peso dos grāos

\begin{tabular}{lrrrc} 
& $\mathrm{g}$ & & & $\mathrm{g}$ \\
Pequenas & 10,6 & 97 & 196 & $\mathbf{2 2 , 7}$ \\
Grandes & 12,9 & 103 & 216 & $\mathbf{2 9 , 2}$ \\
\hline
\end{tabular}

(11) BRASIL. Ministério da Agricultura. Divisão Técnica de Sementes e Mudas. Regras para análise de sementes. (Portaria do Ministério da Agricultura, n. ${ }^{\circ} 532$, de 29/07/76). Brasília, 1976. 188p.

(12) Bataglia, O. C.; MASCARENhas, H. A. A.; Teixeira, J. P. F. \& Tisseli Filho, O. Acúmulo de matéria seca e nutrientes, em soja cultivar santa-rosa. Bragantia, Campinas, $35: 237-247,1976$ 
guma diferença no peso das va. gens vazias e dos grãos. Como não foi observada variação entre os tratamentos quanto ao número de vagens e de grãos, a diferença no peso dos grāos parece ser devida à produção de sementes maiores. Black, citado por BURRIS et alii $\left({ }^{8}\right)$, relata que parece existir uma associação entre o tamanho das sementes plantadas e o das colhidas.
As produções de grãos das plantas no campo foram, respectivamente, 254,6 e $261,7 \mathrm{~g}$ por metro linear para as sementes pequenas e grandes. Como se pode constatar, a diferença na produção de grãos, observada nas plantas crescidas em casa de vegetação, não foi confirmada em condições de campo. SECÃO DE FISIOLOGIA - INSTITUTO AGRONÔMICO, CAMPINAS (SP).

\section{INFLUENCE OF SEED SIZE ON GROWTH AND YIELD OF SOYBEAN PLANTS}

\section{SUMMARY}

Soybean seeds of the santa-rosa cultivar, classified through a 15/64 in. mesh screen (small) and 17/64 in. (large) were planted in pots, in the greenhouse and in the field. From the greenhouse plants, samples were taken 70 and 180 days after planting. In the first sample the following yield components were measured: dry weight of the empty pods number of pods and seeds, and seed weight. Under field conditions only the grain yield was weigted.

The results showed that the seed size apparently did not influence the plant growth under greenhouse conditions. The yield obtained in the greenhouse was proportional to seed size. Under field conditions there was no difference in grain yield between the plots of the two seed sizes. 